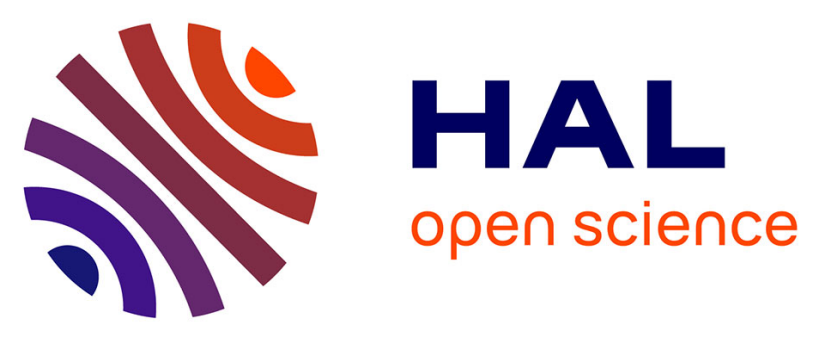

\title{
Secondary prevention of acute coronary events with antiplatelet agents (SPACE-AA): One-year real-world effectiveness and safety cohort study in the French nationwide claims database
}

Patrick Blin, Caroline Dureau-Pournin, Jacques Benichou, Laurent Bonello, Jean Dallongeville, Nicolas Danchin, Bruno Falissard, Florence Thomas-Delecourt, Jérémy Jové, Régis Lassalle, et al.

\section{- To cite this version:}

Patrick Blin, Caroline Dureau-Pournin, Jacques Benichou, Laurent Bonello, Jean Dallongeville, et al.. Secondary prevention of acute coronary events with antiplatelet agents (SPACE-AA): One-year realworld effectiveness and safety cohort study in the French nationwide claims database. Atherosclerosis, 2019, 281, pp.98-106. 10.1016/j.atherosclerosis.2018.11.037 . hal-02898997

\section{HAL Id: hal-02898997 \\ https://hal-amu.archives-ouvertes.fr/hal-02898997}

Submitted on 21 Oct 2021

HAL is a multi-disciplinary open access archive for the deposit and dissemination of scientific research documents, whether they are published or not. The documents may come from teaching and research institutions in France or abroad, or from public or private research centers.
L'archive ouverte pluridisciplinaire HAL, est destinée au dépôt et à la diffusion de documents scientifiques de niveau recherche, publiés ou non, émanant des établissements d'enseignement et de recherche français ou étrangers, des laboratoires publics ou privés.

\section{(ㅇ)(1) $\$$}

Distributed under a Creative Commons Attribution - NonCommerciall 4.0 International 
Version of Record: https:/www.sciencedirect.com/science/article/pii/S0021915018315120

Secondary prevention of acute coronary events with antiplatelet agents (SPACE-AA).

One -year real-world effectiveness and safety cohort study in the French nationwide claims database.

Blin: Ticagrelor, clopidogrel or prasugrel post-MI

Patrick Blin, MD ${ }^{1}$, Caroline Dureau-Pournin, $\mathrm{MSc}^{1}$, Jacques Benichou MD, $\mathrm{PhD}^{2,3}$, Laurent Bonello, $\mathrm{MD}, \mathrm{PhD}^{4}$, Jean Dallongeville $\mathrm{MD}, \mathrm{PhD}^{5}$, Nicolas Danchin $\mathrm{MD}, \mathrm{PhD}^{6}$, Bruno Falissard MD, $\mathrm{PhD}^{7}$, Florence Thomas-Delecourt, $\mathrm{PharmD}^{8}$, Jérémy Jové $\mathrm{MSc}^{1}$, Regis

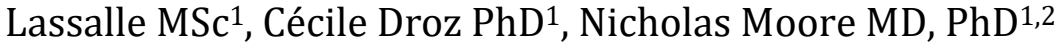

1. Bordeaux PharmacoEpi, University of Bordeaux, INSERM CIC1401, Bordeaux, France

2. INSERM U1219, 33076 Bordeaux, France

3. CHU de Rouen - 76031 Rouen - France

4. Hôpital Nord - 13015 Marseille - France

5. Institut Pasteur de Lille, INSERM U1167, 59019 Lille- France

6. Hopital Européen Georges Pompidou - 75015 Paris - France

7. CESP/INSERM U1018 ? Maison de Solenn ?75679 Paris 14 - France?

8. AstraZeneca France,- 92400 Courbevoie - France?

Corresponding Author: Nicholas Moore, Bordeaux PharmacoEpi, rue Eugène Jacquet 33076 Bordeaux Cedex, France; Tel +33 557571560; fax +33 557574671 nicholas.moore@u-bordeaux.fr 
Abstract

Background and aims: Compare the effectiveness of ticagrelor vs. clopidogrel or prasugrel on recurrence of acute coronary syndromes (ACS) in real-life conditions, as requested by regulatory authorities at the time of marketing.

Methods: A cohort study in SNDS, the French national healthcare database. All patients with a hospital admission for ACS in 2013 were followed one year. Patients on ticagrelor, clopidogrel or prasugrel were matched were matched 1:1, using age, gender, index ACS type, and high-dimensional propensity scores (hdPS). Outcomes were ACS, stroke, all-cause death, and major bleeding, compared within matched groups using Cox proportional hazards models analysis during treatment.

Results: 54048 ACS were hospitalized in 2013. At discharge 19796 were dispensed clopidogrel, 8242 prasugrel, and 13916 ticagrelor. Per group, 9224 ticagrelor vs. clopidogrel, 6752 ticagrelor vs. prasugrel, and 4676 prasugrel vs. clopidogrel patients were matched. Vs. clopidogrel, ticagrelor was associated with a lower hazard ratio of death 0.73 [0.59-0.90] and composite criterion $(0.88,95 \%$ CI [0.79-0.99] but not ACS 0.92 [0.80-1.06], stroke (0.96 [017-5.53]) or major bleeding (1.02 [0.82-1.26]). Prasugrel was not different from ticagrelor or clopidogrel for any outcome, in matched patients.

Conclusions: Ticagrelor in real-life conditions in matched populations was associated with a lower risk of all-cause death than clopidogrel, and a lower risk of the composite outcome, as in the main pivotal clinical trial. Ticagrelor and prasugrel were not different, nor were prasugrel and clopidogrel. 
Keywords: Acute coronary syndrome; secondary prevention; claims database; cohort study antiplatelet agents; ticagrelor

Study registration: www.ENCEPP.eu, EUPAS registration number: EUPAS 5987 


\section{Key Questions:}

- What is already known about this subject?

Clinical trials have found ticagrelor to be superior to clopidogrel in prevention of recurrence of myocardial infarction or death. Ticagrelor and prasugrel have not been adequately compared

- What does this study add?

This study provides real-life comparison of ticagrelor vs. clopidogrel, of ticagrelor vs. prasugrel, and clopidogrel vs. prasugrel. Using ticagrelor after discharge from myocardial infarction was associated with lower all-cause mortality, but no difference in MI recurrence or in stroke or major bleeding. No difference was found between ticagrelor and prasugrel nor between clopidogrel and prasugrel.

How might this impact on clinical practice?

Prescribers can use these results to comfort their clinical decisions. 


\section{Introduction}

Ticagrelor, an orally active antiplatelet agent (APA) acting on the $\mathrm{P}_{2} \mathrm{Y}_{12}$ platelet receptor, $(1,2)$ was found to have an advantage over clopidogrel in secondary prevention after myocardial infarction (MI) in the pivotal clinical trial, PLATO. $(3,4)$ There are few direct comparisons of ticagrelor vs. prasugrel, essentially one short-term underpowered clinical trial that found no difference,(5) a finding replicated in a singlecentre observational study.(6) Indirect comparisons led to conflicting conclusions. (710) Compared to clopidogrel, prasugrel conferred an advantage in mortality and other endpoints after post-MI stenting in the TRITON pivotal trial (11)

Ticagrelor is indicated in Europe in association with low-dose aspirin for secondary prevention after an acute coronary syndrome (unstable angina, non ST elevation, or ST elevation MI), whereas prasugrel is indicated for the prevention of stent thrombosis after PCI.

When ticagrelor was marketed in France, the regulatory authorities requested a real-life study to quantify, over one year, the rates of serious events (death, MI, stroke, major bleeding) in patients treated with ticagrelor compared to competitor drugs (clopidogrel, prasugrel). This study was set up in the French nationwide healthcare system database, SNDS. (12) Prasugrel is used in a different patient population than clopidogrel. Their direct comparison, which was not initially planned, was added post-hoc. The present paper reports on the results of this study, called Secondary Prevention of Acute Coronary Events - antiplatelet Agents or SPACE-AA. 


\section{Methods}

Methods are extensively described in a companion paper submitted to MethodsX

\section{Study objective}

The objectives of this study, Secondary Prevention of Acute Coronary Events with Antiplatelet Agents (SPACE-AA), were to compare in real-life conditions ticagrelor with clopidogrel or prasugrel in the secondary prevention post ACS, on effectiveness and safety endpoints (ACS, stroke, all cause death, bleeding).

\section{Study design}

This was a high-dimensional propensity score matched cohort study(13) in the French nationwide Système National des Données de Santé (SNDS) (12), of all patients hospitalized for an ACS in 2013. Cohort follow-up was one year.

\section{Setting}

The Système National des Données de Santé (SNDS) is a data linkage between SNIIRAM, the nationwide claims database of the French National Healthcare system, PMSI, the national hospital database, and CepiDC, the national death registry. It includes more than $98 \%$ of the French population (66 Million persons) from birth (or immigration) to death (or emigration), even if a subject changes occupations or retires. It contains individual anonymized information on outpatient medical care claims including all reimbursed drugs, information from hospital admissions discharge summaries, and date of death, that are linked to create a longitudinal record of health encounters, hospital diagnoses and drug dispensings. (12) 


\section{Subjects and study size}

All adults with a first hospitalization for acute coronary syndrome (ACS) with ICD-10 codes I20.0 or I21 as primary diagnosis in 2013, in a private or public hospital, with admission to an intensive care unit during the hospital stay, who were alive at discharge and not transferred to a rehabilitation centre were considered for inclusion. Diagnostic codes had been validated in a previous study, with over $85 \%$ positive predictive value.(14) Patients with a history of ACS within 30 days prior to the index hospital admission were excluded. Patients had to have at least one-year history and one-year potential follow-up in the database, or less for patients who died during follow-up. There was no loss to follow-up. Study size was determined empirically as all available subjects over one year in the country.

\section{Variables}

The index date was the date of discharge from the first hospitalization for ACS between 01/01/2013 and 31/12/2013. Baseline demographic and clinical characteristics are described at the index hospitalization, and from the previous year.

\section{Exposure and follow-up}

APA (i.e. clopidogrel, ticagrelor or prasugrel) exposure of interest was defined as the first APA dispensed within 30 days after the index date. The APA exposure period started at the index date and ended 30 days after the end of the dispensed drug supply, at dispensing of a different APA (switch), at death or the occurrence of an event of interest (for that event), or at the end of the follow-up period. 
Usage patterns of ticagrelor, prasugrel, or clopidogrel are described during the year after the index date, whether aspirin was concomitantly dispensed or not.

\section{Outcomes}

Endpoints were all cause death, hospital admission (primary diagnosis) for ACS, stroke, or bleeding. The primary effectiveness endpoint was a composite of ACS, stroke, and death; secondary effectiveness endpoints included the individual items: ACS, stroke, or death; the primary safety endpoint was hospitalization for bleeding. The ICD10 codes used to identify outcomes are described in the online supplementary material appendix I, II, III. They have been used in previous studies of cardiovascular outcomes in that database (15-17)

\section{Confounders.}

In addition to age, sex, social deprivation indicator, type of ACS, index PCI or CABG, duration of hospital stay, days in intensive care, hospital category, previous dispensing of low-dose aspirin or APA, previous ACS, and Charlson comorbidity index (as recommended in this database),(18) more than 500 other empirical variables in 5 main dimensions: (Chronic diseases present at index date; Hospitalisation diagnoses during the year previous to index date; Cardiovascular drugs (7-digit ATC codes) dispensed during the year previous to index date; non-cardiovascular drugs (7 digit ATC codes) in the year previous to index date; Medical or paramedical encounters and lab tests during the year previous to index date) were used to generate high-dimensional propensity scores for statistical analyses (see supplementary online appendix IV and companion methods paper). (19) 
These variables included all previous cardiovascular history and the main confounders such as diabetes (a direct risk factor and a proxy for increased BMI), chronic obstructive pulmonary disease (COPD, a proxy for chronic severe smoking), ACS prior to inclusion, atrial fibrillation, heart failure, renal disease, hypertension, peripheral arterial disease or cancer, which have been found to be associated with outcomes such as death or recurrence of ACS in a previous study. (16)

\section{Statistical analyses}

All analyses were pre-specified and described in a statistical analysis plan before beginning the study, which was registered with the European Medicines Agency EUPAS database prior to start of study, for ticagrelor vs. clopidogrel and ticagrelor vs. Prasugrel. The comparison of prasugrel vs. clopidogrel was not initially prespecified, and was added post hoc at the request of a reviewer. It was done in exactly the same manner as the two initially prespecified comparisons.

In brief, hdPS were determined for each drug pair (ticagrelor vs. clopidogrel, ticagrelor vs. prasugrel, clopidogrel vs. prasugrel). The methodology of hdPS is described in supplementary material document 1 : statistical analysis plan and in the companion MethodsX paper. The variables included in hdPS were selected according to standard procedures, on the tightness of their association with outcomes, using logistic regression $(13,19)$ The variables included in the hdPS are provided in the supplementary material (supplementary material appendix 4).

Patients were matched 1:1 on gender, age at index date, type of index ACS (unstable angina, ST-elevated myocardial infarction (STEMI), non-ST elevated myocardial 
infarction (NSTEMI)) and hdPS, using greedy nearest neighbour matching. Goodness of match was assessed by the hdPS distributions in unmatched and matched populations (complementary Figure S1) and by standardized mean differences in unmatched and matched populations (Complementary Figures S2 and S3).(20)

The unmatched (crude) population descriptions for all patients considered for the study (including other antiplatelet agents) are shown in supplementary table S1. Main baseline characteristics in matched populations are shown in table 2 Event rates were computed in matched populations using Kaplan Meier methods. Rates were computed during exposure, as defined above. Patients were censored for each individual outcome at first occurrence, at death, upon cessation of exposure or at end of study period. There was no missing data, and no loss to follow-up within the study population. Main outcomes in crude populations are shown in supplementary table S2

The main statistical analysis relied on Cox proportional hazards ratios comparisons of hdPS-matched cohorts. Hazard ratios for events in matched populations are shown in figures 1 to 3 .

The generalizability of the results in matched population to the entire treated populations was tested using adjusted Cox proportional hazards or Fine and Gray models with the same variables used for matching (among which age, gender, type of ACS, and hdPS). The forest plots for these different adjustments are shown in figures S5 and S6.

Hazard ratios were also analysed according to the type of initial ACS (all ACS, Unstable angina, STEMI and NSTEMI) (figure S7). 
Statistical analysis was conducted by Bordeaux PharmacoEpi, a research platform of University of Bordeaux, using SAS ${ }^{\circledR}$ software (SAS Institute, Version 9.4, North Carolina, USA).

The authors had full access to all the data used in this analysis

Study authorization and registration.

This study was authorized by the National Commission on Informatics and Liberties (CNIL) on 9 October 2014, Number 1739312. No individual patient information or consent was required

This study was registered with the European Union Post-Authorization Studies registry (EUPAS) under $\mathrm{N}^{\circ}$ EUPAS5987 at www.encepp.eu. 


\section{Results}

In 2013, 76,844 patients had an ICD10 hospital diagnostic code for ACS and an ICU stay during index hospitalization; 54,097 were included in the study population with 19,796 (36.6\%) on clopidogrel, $13,916(25.7 \%)$ on ticagrelor, and $8,242(15.2 \%)$ on prasugrel

(Table 1). Ticagrelor patients were younger than clopidogrel but older than prasugrel. Over $90 \%$ of prasugrel users had had a percutaneous coronary intervention, consistent with stent thrombosis prevention (supplementary Table S1). Most patients had their first outpatient APA dispensing on the day of hospital discharge. The one-year cumulative incidence of discontinuation or switch of the initial APA was 37.3\% (95\% CI [36.5-38.1]) for ticagrelor, 35.7\% [35.0-36.3] for clopidogrel, and 29.2\% [28.2-30.2] for prasugrel. There is no knowledge of the reasons for stopping or switching drugs. The crude one-year cumulative risks for outcomes overall and per initial diagnosis group are in supplementary table S2. As expected, the older (mean age 74) clopidogrel patients had more ACS, stroke, deaths and major bleeding than patients on ticagrelor (mean age63) or prasugrel (mean age 58).

9,224 ticagrelor patients (71\% of all ticagrelor patients) were matched to 9224 clopidogrel patients (47\%), 6752 each for ticagrelor (49\%) and prasugrel (82\%), and 4676 each for prasugrel (34\%) vs. clopidogrel (24\%) (Table 2). Distributions of hdPS in unmatched and matched populations are shown in supplementary figure S1 for the comparisons with ticagrelor and in supplementary figure S2 for clopidogrel vs. prasugrel. Standardized mean differences are shown in table 2 for the main parameters, and in supplementary figures S3 and S4 for all 500 parameters for the two comparisons with ticagrelor. None exceeded 1\% (20). 
Patients exposed to ticagrelor had a significantly lower relative risk of the composite outcome (Hazard ratio 0.88, 95\%CI [0.79-0.99]) and all-cause death $(0.73$ [0.59-0.90]) than matched patients exposed to clopidogrel. There was no difference in ACS, stroke or major bleeding (Figure 1).

There was no difference between patients on ticagrelor vs. matched patients on prasugrel for any of the outcomes (Figure 2).

There was no significant difference between matched patients on prasugrel vs. clopidogrel for any of the outcomes (Figure 3). Point estimates were lower with prasugrel, and similar to those observed with ticagrelor vs. clopidogrel, but confidence intervals were wider because of the small matched population.

Results were similar with adjusted analyses, for ticagrelor vs. clopidogrel (supplementary figures S5), or vs. prasugrel (supplementary figure S6) and for each initial diagnosis category (supplementary figure S7) Considering the small overlap of the populations of clopidogrel vs. prasugrel, we did not analyse adjusted models on the whole population.

Events were more common during the first three months of follow-up (supplementary figure S8) 


\section{Discussion}

The objective of SPACE-AA was to study the one-year effectiveness and safety of ticagrelor in France, compared to clopidogrel or prasugrel in the secondary prevention of coronary events. Most of the patients had PCI, and the vast majority had full quadritherapy for secondary prevention, as described in other studies. $(15,17,21)$ We did not consider the in-hospital use of and outcomes associated with APA at the time of the initial ACS. Our objective was to study the real-life performance of ticagrelor compared to clopidogrel over one year after discharge from the hospital as recommended, (22), with reference to the pivotal trial, PLATO, (3) and to the Swedeheart registry, $(3,23,24)$ and to compare ticagrelor and prasugrel. In a post-hoc analysis we also compared clopidogrel and prasugrel, even though they were used in very different populations with little overlap.

The usage patterns of the APA in SPACE-AA were consistent with guidelines and marketing authorizations. Prasugrel was prescribed almost exclusively after PCI in younger, predominantly male patients, and clopidogrel in older patients. Ticagrelor was used in a wider array of patients, which allowed us to find sizable matched populations of patients vs. prasugrel and clopidogrel. To this intent, we selected 500 variables among the several thousand variables available in the database that were considered to develop the hdPS, using standard high-dimensional propensity score methods. (25) We also used a modified Charlson score which is highly predictive of fatal outcomes, (18) and the variables associated with death or ACS recurrence in similar patients in a previous study. (16) 
In these highly matched patients we found that the use of ticagrelor was associated with fewer all-cause deaths and composite events than clopidogrel. There was no significant difference in the recurrence of ACS, nor in stroke, or major bleeding. A lower death rate with ticagrelor, with no difference in rates of ACS recurrence may point to competing risk effect, whereby lower death rates may result in more ACS survivors with ticagrelor. These results are consistent with the post-hospitalization period in the PLATO trial, (3, 4) despite slightly different baseline population profiles. In PLATO the hazard ratio for all-cause death was 0.81 [0.68-0.95] compared to 0.73 [0.59-0.90] here. All-cause death rate was $5.0 \%$ in PLATO compared to $6.1 \%$ here. We had already found a higher death rate in our post-MI patients than in the patients in the Pegasus-TIMI54 study.(16) Similarly, stroke was less common in SPACE-AA (0.9\%) than in PLATO (1.2\%), findings noted in long-term post-infarction outcome studies. $(16,26)$ SWEDEHEART is an observational study in the Swedish MI registry, which did not resort to hdPS matching but to standard adjustment techniques.(27) In addition for about half the time of Swedeheart only clopidogrel was available, so that the effects of ticagrelor might have also been confounded by changes over time in outcomes, (28) possibly explaining $12 \%$ death rates for clopidogrel compared to $6 \%$ for ticagrelor. In SWEDEHEART adjusted HR for death was 0.83 [0.78-0.93], but the difference in MI recurrence did not quite reach significance $(0.89$ [0.78-1.01] compared to $0.92[0.80 ; 1.06]$ in SPACE-AA). In SWEDEHEART there was a higher risk of bleeding in ticagrelor patients (HR 1.20 [1.041.40]), which was found neither in PLATO (0.99 [0.89-1.10]) nor in SPACE-AA (1.02 [0.82-1.26]). As in SWEDEHEART and PLATO, about half of the events in SPACE-AA occurred in the first weeks of follow-up, within 3 months of the initial event There are few direct comparisons of ticagrelor vs. prasugrel.(3, 5-10, 29-31) We found no difference between event rates in matched patients on ticagrelor or prasugrel, 
concerning death or any other outcome. Our confidence intervals are narrow and fall within or near the usual equivalence bands except for stroke, of which there were so few that it was next to impossible to have a precise estimate, replicating previous findings. (16) The comparison of prasugrel with clopidogrel found no significant differences. Even though all point estimates were in favour of prasugrel over clopidogrel, the number of events were too small to provide enough power or precision to reach significance. The patients prescribed prasugrel or clopidogrel were so different that few patients could be matched and compared, and therefore the applicability of this comparison should not be more than tentative.

\section{Limitations and strengths:}

This study has the limits and strengths of claims databases studies:

The main strength of database studies, in addition to size and representativeness, is that the data in the SNIIRAM claims database are acquired prospectively, continuously, automatically and independently from this or any other study. Patients are followed lifelong, whatever their social or professional situation or age, and there are no loss to follow-up.

However, there are well-known limits: there is limited clinical information.(12) Patient outcomes are determined from hospital discharge summaries. These are not the individually adjudicated outcomes of clinical trials. The codes used for acute coronary syndromes or stroke have been verified $(14,32)$ and used in other studies in the same database $(15,16,21)$. Coding in the hospitals is subject to routine quality control and regular audits by local, regional and national stakeholders. (33) Errors in the diagnostic codes for selection, matching and outcome might reduce precision, but would not create 
bias unless there were systematic preferential attribution of a diagnostic code based on exposure to a given drug. Death data comes from the national death registry, and although cause of death is not reported, all-cause death can be considered a robust outcome. It was the one most affected by ticagrelor vs. clopidogrel.

Unmeasured confounders may result in residual confounding, which could explain some of the results, especially since the differences, even if of similar magnitude to those found in the clinical trial, may be thought small, with NNT to observe one fewer death $>200$, or $>100$ for the combined criterion. On the other hand, there is a clear contrast between the matched and the crud results. (supplementary table S5) The crude HR for the composite was 0.51 [0.47-0.55] and for death 0.25 [0.21-0.29].

Though a confounder may not be directly measured, other variables are which may be associated with the unmeasured factors: this is the basis for hdPS. (13) There are proxies for unmeasured risk factors such as smoking or body mass index. Chronic obstructive lung disease is highly correlated with the chronic heaving smoking, and was a major risk factor for repeat ACS in post-MI patients. (16) Type 2 diabetes, presumably also a proxy for BMI, was another such risk factor for recurrence of ACS (16) To be a confounder, a factor must be associated with the outcome and with the exposure, i.e., the choice of the drug must depend on this confounder. This may be the case for PCI and prasugrel, but PCI is captured and was adjusted or matched for. Smoking or polymedication may be a reason to choose ticagrelor rather than clopidogrel, because of the risk of interactions with clopidogrel. This would result in putting higher-risk patients on ticagrelor, which is not what we found. We also included poly-medication in the hdPS. Matching by hdPS selects patients who are very similar on a large number of variables. This can be seen by the distribution of the propensity scores before and after matching 
(see supplementary figures S1), or the standardized mean differences before and after matching (supplementary figure S3). The generalizability of the results obtained in the matched populations to the whole population is ascertained by computation of hazard ratios using whole population analyses, adjusted on the same criteria as the matching. Because there is an overlap in the propensity scores over the whole range of the score (figure S1), there were no excluded or extrapolated patients. This was not true for clopidogrel vs. prasugrel, where the overlap was small (supplementary figure S2) and fewer than half the patients of the smaller population were matched. The large number of variables used for hdPS raises the risk of overfitting and collinearity. Overfitting was avoided by adjusting the number of variables considered in the hdPS to the number of patients. Collinearity is systematically tested and taken into account, as is the proportionality of hazard, testing for time interactions. All these verifications are automated and built into the statistical analysis routines.

Exposures are determined from dispensing, which provides the name of the drug preparation, strength and number of tablets dispensed. Exposure is derived from dispensing, with a 30-day grace period after the theoretical end of the dispensed supply to take into account possible drug hoarding. Dispensing is not necessarily exposure, but is one step closer to actual exposure than prescription. It also ensures that at the very least the patient had access to the drug, and avoids recollection bias. The issue of compliance, i.e. the link between buying, or being given the drug, and actually using it is a constant problem in drug-related clinical research, including clinical trials. Having taken possession of the drug is a reasonable proxy for exposure, especially if the dispensing is regularly repeated, as is the case here. 
Comparisons are tentative since the attribution of treatment was not randomized. We describe event rates in patient populations exposed to the different drugs, populations which were identical over a wide range of variables.

The representativeness of our study populations is certain, since SNDS includes over $98 \%$ of the French population.

\section{Conclusion}

This nation-wide hdPS matched cohort study confirmed that in similar patients ticagrelor was associated with fewer deaths or composite endpoints than clopidogrel, and that there was no difference with prasugrel, nor between prasugrel and clopidogrel, in France, at that time. 


\section{Conflicts of Interest:}

Bordeaux PharmacoEpi (INSERM CIC1401) has received funding from AstraZeneca for a previous study of long-term outcomes after myocardial infarction, in which most of the algorithms used in the present study were tested. (16) The contracts for all studies done by Bordeaux PharmacoEpi are signed by the president of the University of Bordeaux, which manages all the financial aspects pertaining to these studies.

NM has no other relevant disclosure.

PB, CDP, JJ, RL, CD have no relevant disclosures.

JB reports no disclosures

LB reports no disclosure relevant to this study.

JD has received modest consultant fees for other pharmacoepidemiological studies from AstraZeneca, on topics related to the present study.

ND reports no relevant disclosures pertaining to this study.

BF has been consultant for AstraZeneca reporting modest fees

FT is a salaried employee of AstraZeneca.

\section{Financial support:}

This study was supported by AstraZeneca. It was done at the request of the French regulatory authorities, which reviewed and approved the study protocol, and received the study report. AstraZeneca had no role in the study design, management, data acquisition, analysis or the decision to write or submit this paper.

\section{Author contributions}

Study design: PB, NM, JB, LB, JD, ND, BF, RL, CD.

Study management: CDP, CD, PB, RL 
Data extractions, management and analysis: JJ, RL, PB, CDP

Interpretation and discussion of results: PB, NM, JB, LB, JD, ND, BF, RL, CD, FTD

Report generation: CDP, PB, JJ, RL

Manuscript generation: NM, CDP

Manuscript discussion and final approval: all authors

\section{Acknowledgements:}

The authors would like to acknowledge the support of ADERA, a non-profit organization that provided human resources, management capabilities and legal support to Bordeaux PharmacoEpi. 
References:

1. Deeks ED. Ticagrelor: a review of its use in the management of acute coronary syndromes. Drugs. 2011;71(7):909-33.

2. Husted S, van Giezen JJ. Ticagrelor: the first reversibly binding oral P2Y12 receptor antagonist. Cardiovasc Ther. 2009;27(4):259-74.

3. Cannon CP, Harrington RA, James S, Ardissino D, Becker RC, Emanuelsson H, et al. Comparison of ticagrelor with clopidogrel in patients with a planned invasive strategy for acute coronary syndromes (PLATO): a randomised double-blind study. Lancet. 2010;375(9711):283-93.

4. Wallentin L, Becker RC, Budaj A, Cannon CP, Emanuelsson H, Held C, et al. Ticagrelor versus clopidogrel in patients with acute coronary syndromes. N Engl J Med. 2009;361(11):1045-57.

5. Motovska Z, Hlinomaz O, Miklik R, Hromadka M, Varvarovsky I, Dusek J, et al. Prasugrel Versus Ticagrelor in Patients With Acute Myocardial Infarction Treated With Primary Percutaneous Coronary Intervention: Multicenter Randomized PRAGUE-18 Study. Circulation. 2016;134(21):1603-12.

6. Gosling R, Yazdani M, Parviz Y, Hall IR, Grech ED, Gunn JP, et al. Comparison of P2Y12 inhibitors for mortality and stent thrombosis in patients with acute coronary syndromes: Single center study of 10793 consecutive 'real-world' patients. Platelets. 2017;28(8):1-7.

7. Bavishi C, Panwar S, Messerli FH, Bangalore S. Meta-Analysis of Comparison of the Newer Oral P2Y Inhibitors (Prasugrel or Ticagrelor) to Clopidogrel in Patients With Non-ST-Elevation Acute Coronary Syndrome. Am J Cardiol. 2015.

8. Lee YS, Jin CD, Kim MH, Guo LZ, Cho YR, Park K, et al. Comparison of Prasugrel and Ticagrelor Antiplatelet Effects in Korean Patients Presenting With ST-Segment Elevation Myocardial Infarction. Circ J. 2015;79(6):1248-54.

9. Steiner S, Moertl D, Chen L, Coyle D, Wells GA. Network meta-analysis of prasugrel, ticagrelor, high- and standard-dose clopidogrel in patients scheduled for percutaneous coronary interventions. Thromb Haemost. 2012;108(2):318-27.

10. Briasoulis A, Telila T, Palla M, Siasos G, Tousoulis D. P2Y12 Receptor Antagonists: Which One to Choose? A Systematic Review and Meta-Analysis. Curr Pharm Des. 2016;22(29):4568-76.

11. Montalescot G, Wiviott SD, Braunwald E, Murphy SA, Gibson CM, McCabe CH, et al. Prasugrel compared with clopidogrel in patients undergoing percutaneous coronary intervention for ST-elevation myocardial infarction (TRITON-TIMI 38): double-blind, randomised controlled trial. Lancet. 2009;373(9665):723-31.

12. Bezin J, Duong M, Lassalle R, Droz C, Pariente A, Blin P, et al. The national healthcare system claims databases in France, SNIIRAM and EGB: Powerful tools for pharmacoepidemiology. Pharmacoepidemiol Drug Saf. 2017;26(8):954-62.

13. Schneeweiss S, Rassen JA, Glynn RJ, Avorn J, Mogun H, Brookhart MA. Highdimensional propensity score adjustment in studies of treatment effects using health care claims data. Epidemiology. 2009;20(4):512-22.

14. Bezin J, Girodet PO, Rambelomanana S, Touya M, Ferreira P, Gilleron V, et al. Choice of ICD-10 codes for the identification of acute coronary syndrome in the French hospitalization database. Fundam Clin Pharmacol. 2015;29(6):586-91.

15. Bezin J, Groenwold RH, Ali MS, Lassalle R, Robinson P, de Boer A, et al.

Comparative effectiveness of recommended versus less intensive drug combinations in 
secondary prevention of acute coronary syndrome. Pharmacoepidemiol Drug Saf. 2017;26(3):285-93.

16. Blin P, Dureau-Pournin C, Lassalle R, Jove J, Thomas-Delecourt F, Droz-Perroteau $\mathrm{C}$, et al. Outcomes in Post-Myocardial Infarction patients similar to those of the PEGASUS-TIMI 54 trial: a cohort study in the French national claims database. Br J Clin Pharmacol. 2017;83(9):2056-65.

17. Puymirat E, Riant E, Aissoui N, Soria A, Ducrocq G, Coste P, et al. beta blockers and mortality after myocardial infarction in patients without heart failure: multicentre prospective cohort study. BMJ. 2016;354:i4801.

18. Bannay A, Chaignot C, Blotiere PO, Basson M, Weill A, Ricordeau P, et al. The Best Use of the Charlson Comorbidity Index With Electronic Health Care Database to Predict Mortality. Med Care. 2016;54(2):188-94.

19. Rassen JA, Glynn RJ, Brookhart MA, Schneeweiss S. Covariate selection in highdimensional propensity score analyses of treatment effects in small samples. Am J Epidemiol. 2011;173(12):1404-13.

20. Austin PC. Balance diagnostics for comparing the distribution of baseline covariates between treatment groups in propensity-score matched samples. Stat Med. 2009;28(25):3083-107.

21. Bezin J, Pariente A, Lassalle R, Dureau-Pournin C, Abouelfath A, Robinson P, et al. Use of the recommended drug combination for secondary prevention after a first occurrence of acute coronary syndrome in France. Eur J Clin Pharmacol. 2014;70(4):429-36.

22. Ibanez B, James S, Agewall S, Antunes MJ, Bucciarelli-Ducci C, Bueno H, et al. 2017 ESC Guidelines for the management of acute myocardial infarction in patients presenting with ST-segment elevation: The Task Force for the management of acute myocardial infarction in patients presenting with ST-segment elevation of the European Society of Cardiology (ESC). Eur Heart J. 2018;39(2):119-77.

23. Pareek M, Bhatt DL. Ticagrelor for patients with acute coronary syndromes: PLATOnic affair or lasting SWEDEHEART? Eur Heart J. 2016;37(44):3343-6.

24. Sahlen A, Varenhorst C, Lagerqvist B, Renlund H, Omerovic E, Erlinge D, et al. Outcomes in patients treated with ticagrelor or clopidogrel after acute myocardial infarction: experiences from SWEDEHEART registry. Eur Heart J. 2016;37(44):3335-42. 25. Schneeweiss S, Eddings W, Glynn RJ, Patorno E, Rassen J, Franklin JM. Variable Selection for Confounding Adjustment in High-dimensional Covariate Spaces When Analyzing Healthcare Databases. Epidemiology. 2017;28(2):237-48.

26. Blin P, Philippe F, Bouee S, Laurendeau C, Torreton E, Gourmelin J, et al. Outcomes following acute hospitalised myocardial infarction in France: An insurance claims database analysis. Int J Cardiol. 2016;219:387-93.

27. Jernberg T, Attebring MF, Hambraeus K, Ivert T, James S, Jeppsson A, et al. The Swedish Web-system for enhancement and development of evidence-based care in heart disease evaluated according to recommended therapies (SWEDEHEART). Heart. 2010;96(20):1617-21.

28. Tunstall-Pedoe H, Kuulasmaa K, Mahonen M, Tolonen H, Ruokokoski E, Amouyel P. Contribution of trends in survival and coronary-event rates to changes in coronary heart disease mortality: 10-year results from 37 WHO MONICA project populations. Monitoring trends and determinants in cardiovascular disease. Lancet. 1999;353(9164):1547-57. 
29. Serebruany V, Cherepanov V, Dukhanin A. Significant excess of early deaths after prehospital ticagrelor: The ATLANTIC trial challenge. Thromb Haemost. 2015;114(1):78.

30. Serebruany VL, Cherepanov V, Tomek A, Kim MH. Among antithrombotic agents, prasugrel, but not ticagrelor, is associated with reduced 30day mortality in patients with ST-elevated myocardial infarction. Int J Cardiol. 2015;195:104-10.

31. Lhermusier T, Lipinski MJ, Tantry US, Escarcega RO, Baker N, Bliden KP, et al. Meta-analysis of direct and indirect comparison of ticagrelor and prasugrel effects on platelet reactivity. Am J Cardiol. 2015;115(6):716-23.

32. Giroud M, Hommel M, Benzenine E, Fauconnier J, Bejot Y, Quantin C, et al. Positive Predictive Value of French Hospitalization Discharge Codes for Stroke and Transient Ischemic Attack. Eur Neurol. 2015;74(1-2):92-9.

33. Gilleron V, Gasnier-Duparc N, Hebbrecht G. Certification des comptes: Une incitation à la traçabilité des processus de contrôle. Revue Hospitaliere de France. 2018;582:42-6. 
Figure Legends

Figure 1 Forest plots of hazard ratios with 95\% CI, ticagrelor vs. clopidogrel in the hdPSmatched populations

Figure 2 Forest plots of hazard ratios with 95\% CI, ticagrelor vs. prasugrel in the hdPSmatched populations

Figure 3 Forest plots of hazard ratios with 95\% CI, clopidogrel vs. prasugrel in the hdPSmatched populations 
Supplementary online material:

Supplementary material 1:Statistical analysis plan, from the study protocol.

Supplementary material 2:

Appendix I: list of ICD-10 codes for Acute coronary syndrome

Appendix II: list of ICD-10 codes for ischemic or undefined stroke Appendix III: list of ICD-10 codes for major bleeding

Appendix IV: list of variables used for the high-dimensional propensity score

matching

Supplementary material 3: tables and figures:

Supplementary Table S1: Patient characteristics at inclusion

Supplementary Table S2: Crude incidence (in person-years) of outcomes during the exposure period according to the antiplatelet agent treatment dispensed in the 30 days after index date for each diagnosis of the index hospitalization.

Supplementary Figure S1: distribution of high-dimensional propensity scores in unmatched (upper panels) and matched (lower panels) ticagrelor vs. clopidogrel (left panels) and ticagrelor vs. prasugrel (right panels) patients.

Supplementary Figure S2: distribution of high-dimensional propensity scores for prasugrel (blue), vs. clopidogrel (red)

Supplementary Figure S3: Standardized differences in characteristics $(n=516)$ included in the hdPS (before and after matching): Ticagrelor vs. Clopidogrel

Supplementary figure S4 Standardized differences in characteristics $(n=516)$ included in the hdPS (before and after matching): Ticagrelor vs. Prasugrel

Supplementary figure S5 Forest plots of the crude, adjusted and matched hazard ratios associated with ticagrelor vs. clopidogrel for individual and composite outcomes:

Supplementary figure S6 Forest plots of the crude, adjusted and matched hazard ratios associated with ticagrelor vs. prasugrel for individual and composite outcomes:

Supplementary Figure S7 Forest plots of the hazard ratios associated with ticagrelor vs. clopidogrel and ticagrelor vs. prasugrel for individual and composite outcomes for each initial diagnostic group, in the different study populations, including crude, minimally adjusted, fully adjusted and matched analyses

Supplementary Figure S8: One-year cumulative incidence (Kaplan-Meier) of outcomes during the APA exposure period (on treatment) according to the APA treatment in the matched populations 
Table 1: study populations

\begin{tabular}{|c|c|}
\hline & $\begin{array}{l}\text { Study Population } \\
\text { n }\end{array}$ \\
\hline $\begin{array}{l}\text { Selection criteria } \\
\text { - First hospitalisation with I20.0 or I } 21 \text { primary diagnosis } \\
\text { - Between } 1^{\text {st }} \text { January } 2013 \text { and } 31 \text { December } 2013 \\
\text { - Without history of ACS (I20.0, I21-24) in the } 30 \text { days before } \\
\text { - In a teaching/regional hospital, other public or private } \\
\text { hospital } \\
\text { - With or without at least one day in an intensive care unit } \\
\text { - With at least one day in an intensive care unit }\end{array}$ & 76844 \\
\hline Exclusion criteria & 22747 \\
\hline $\begin{array}{l}\text { - Index hospitalisation duration = } 0 \text { day and alive at } \\
\text { discharge }\end{array}$ & 748 \\
\hline - Uncertain identification (several twins or beneficiaries) & 68 \\
\hline - Less than 18 years at index date & 6 \\
\hline - Less than 365 days of history in SNIIRAM before index date & 2095 \\
\hline - Death during index hospitalisation & 3911 \\
\hline $\begin{array}{l}\text { - Alive at discharge and without any reimbursed healthcare } \\
\text { in the } 365 \text { days after index date }\end{array}$ & 1888 \\
\hline - Rehabilitation centre in the 30 days after index date & 14031 \\
\hline Study Populations: initial APA & 54097 \\
\hline - Clopidogrel $( \pm$ ASA $)$ & 19796 \\
\hline - Ticagrelor ( \pm ASA) & 13916 \\
\hline - Prasugrel $( \pm$ ASA $)$ & 8242 \\
\hline - ASA alone & 7068 \\
\hline - No APA (no dispensation within 30 days after discharge) & 5026 \\
\hline - Others: other APA or association of several APA $( \pm$ ASA) & 49 \\
\hline \multicolumn{2}{|l|}{ Matched populations } \\
\hline Ticagrelor versus clopidogrel (per group) & 9224 \\
\hline Ticagrelor versus prasugrel (per group) & 6752 \\
\hline Clopidogrel vs. prasugrel (per group) & 4676 \\
\hline
\end{tabular}

APA: antiplatelet agent.

ASA: aspirin 
Table 2: Main Baseline characteristics of matched patients at index date according to the first antiplatelet agent treatment dispensed in the 30 days after index date.

\begin{tabular}{|c|c|c|c|c|c|c|c|c|c|}
\hline & $\begin{array}{l}\text { Clopidogrel } \\
\mathrm{n}=9224\end{array}$ & $\begin{array}{l}\text { Ticagrelor } \\
\mathrm{n}=9224\end{array}$ & $\begin{array}{l}\text { Standardized } \\
\text { Difference } \\
(\%)\end{array}$ & $\begin{array}{l}\text { Prasugrel } \\
n=6752\end{array}$ & $\begin{array}{l}\text { Ticagrelor } \\
\mathrm{n}=6752\end{array}$ & $\begin{array}{l}\text { Standardized } \\
\text { Difference } \\
(\%)\end{array}$ & $\begin{array}{l}\text { Clopidogrel } \\
\mathrm{n}=4676\end{array}$ & $\begin{array}{l}\text { Prasugrel } \\
n=4676\end{array}$ & $\begin{array}{l}\text { Standardized } \\
\text { Difference } \\
\text { (\%) }\end{array}$ \\
\hline Gender Male, n (\%) & $6776(73.5)$ & $6776(73.5)$ & 0.0 & $5732(84.9)$ & $5732(84.9)$ & 0.0 & $3842(82.2)$ & $3842(82.2)$ & 0.0 \\
\hline Age (in years), mean (sd) & $66.5(12.4)$ & $66.5(12.4)$ & 0.0 & $58.5(10.0)$ & $58.4(10.0)$ & -0.1 & $60.3(10.1)$ & $60.3(10.1)$ & 0.0 \\
\hline \multicolumn{10}{|l|}{$\begin{array}{l}\text { Primary diagnosis of the index ACS } \\
\text { hospitalization, } n(\%)\end{array}$} \\
\hline Unstable angina & 2894 (31.4) & $2894(31.4)$ & 0.0 & $1246(18.5)$ & $1246(18.5)$ & 0.0 & $1236(26.4)$ & $1236(26.4)$ & 0.0 \\
\hline STEMI & $4730(51.3)$ & $4730(51.3)$ & 0.0 & $4917(72.8)$ & $4917(72.8)$ & 0.0 & $2882(61.6)$ & $2882(61.6)$ & 0.0 \\
\hline NSTEMI & $1600(17.3)$ & $1600(17.3)$ & 0.0 & $589(8.7)$ & $589(8.7)$ & 0.0 & $558(11.9)$ & $558(11.9)$ & 0.0 \\
\hline $\begin{array}{l}\text { Percutaneous coronary intervention during } \\
\text { index hospitalization } n(\%)\end{array}$ & $7810(84.7)$ & 7793 (84.5) & -0.5 & 6365 (94.3) & $6382(94.5)$ & 1.1 & $4232(90.5)$ & $4276(91.4)$ & 3.3 \\
\hline $\begin{array}{l}\text { Coronary artery bypass graft during index } \\
\text { hospitalization *, n (\%) }\end{array}$ & $19(0.2)$ & $14(0.2)$ & - & $1(0.0)$ & $0(0.0)$ & - & $3 \quad(0.1)$ & $3(0.1)$ & - \\
\hline First ACS/ APA naïve , n (\%) & $6721(72.9)$ & $6791(73.6)$ & 0.5 & $5390(79.8)$ & $5415(80.2)$ & 0.9 & $3492(74.7)$ & $3516(75.2)$ & 1.2 \\
\hline \multicolumn{10}{|l|}{$\begin{array}{l}\text { Charlson comorbidity index (in } \\
\text { categories), n (\%) }\end{array}$} \\
\hline$[0-1]$ & $314(3.4)$ & $325(3.5)$ & 0.7 & $218(3.2)$ & $198(2.9)$ & -1.7 & $153 \quad(3.3)$ & $188 \quad(4.0)$ & 4.0 \\
\hline$[2-3]$ & 2202 (23.9) & 2315 (25.1) & 2.8 & 2805 (41.5) & $2729(40.4)$ & -2.3 & $1543(33.0)$ & 1658 (35.5) & 5.2 \\
\hline
\end{tabular}




\begin{tabular}{|c|c|c|c|c|c|c|c|c|c|c|}
\hline & & $\begin{array}{c}\text { Clopidogrel } \\
\mathbf{n}=9224\end{array}$ & $\begin{array}{c}\text { Ticagrelor } \\
\mathrm{n}=9224\end{array}$ & $\begin{array}{c}\text { Standardized } \\
\text { Difference } \\
(\%)\end{array}$ & $\begin{array}{l}\text { Prasugrel } \\
\mathrm{n}=6752\end{array}$ & $\begin{array}{l}\text { Ticagrelor } \\
\mathrm{n}=6752\end{array}$ & $\begin{array}{c}\text { Standardized } \\
\text { Difference } \\
\text { (\%) }\end{array}$ & $\begin{array}{c}\text { Clopidogrel } \\
n=4676\end{array}$ & $\begin{array}{l}\text { Prasugrel } \\
\mathrm{n}=4676\end{array}$ & $\begin{array}{l}\text { Standardized } \\
\text { Difference } \\
\text { (\%) }\end{array}$ \\
\hline [4-5] & & $3170(34.4)$ & $3014(32.7)$ & -3.6 & $2337(34.6)$ & $2604(38.6)$ & 8.2 & $1899(40.6$ & $1627(34.8)$ & -12.0 \\
\hline$[6-7]$ & & $2275(24.7)$ & $2302(25.0)$ & 0.7 & $1030(15.3)$ & $971(14.4)$ & -2.5 & $777(16.6$ & $844(18.0)$ & 3.8 \\
\hline$>7$ & & $1263(13.7)$ & $1268(13.7)$ & 0.2 & $362(5.4)$ & $250(3.7)$ & -8.0 & $304(6.5$ & $359 \quad(7.7)$ & 4.6 \\
\hline \multicolumn{11}{|c|}{ Long term disease registrations at inclusion } \\
\hline $\begin{array}{l}\text { At least one LTD declared before in } \\
\text { dex ACS hospitalisation, } n(\%)\end{array}$ & 7550 & $(81.9)$ & $7666(83.1)$ & 3.3 & $5562(82.4)$ & $5575(82.6)$ & 0.5 & $3793(81.1)$ & $3848(82.3)$ & 3.0 \\
\hline LTD 13: Coronary heart disease & 5380 & $(58.3)$ & $5693(61.7)$ & 6.9 & $4554(67.4)$ & $4612(68.3)$ & 1.8 & $2915(62.3)$ & $3035(64.9)$ & 5.3 \\
\hline $\begin{array}{l}\text { LTD 8: Diabetes type 1, diabetes } \\
\text { type } 2\end{array}$ & 1641 & $(17.8)$ & $1611(17.5)$ & -0.9 & $1075(15.9)$ & $986(14.6)$ & -3.7 & $807(17.3)$ & $786(16.8)$ & -1.2 \\
\hline $\begin{array}{l}\text { LTD 30: Malignant tumours, mali } \\
\text { gnant lymphatic or haematopoietic } \\
\text { tissue }\end{array}$ & 947 & $(10.3)$ & $975(10.6)$ & 1.0 & 415 (6.1) & 388 (5.7) & -1.7 & $344 \quad(7.4)$ & $354(7.6)$ & 0.8 \\
\hline \multicolumn{11}{|c|}{ Hospitalisation in the year before index ACS hospitalisation, n (\%) } \\
\hline At least one hospitalisation & 3098 & $(33.6)$ & $2970(32.2)$ & -3.0 & $1570(23.3)$ & $1554(23.0)$ & -0.6 & $1349(28.8)$ & $1318(28.2)$ & -1.5 \\
\hline Diseases of the circulatory system & 1115 & $(12.1)$ & $1103(12.0)$ & -0.4 & 462 (6.8) & $477 \quad(7.1)$ & 0.9 & $443 \quad(9.5)$ & $439 \quad(9.4)$ & -0.3 \\
\hline $\begin{array}{l}\text { I25 (Chronic ischaemic heart dise } \\
\text { ase) }\end{array}$ & 179 & $(1.9)$ & $194 \quad(2.1)$ & 1.2 & $86 \quad(1.3)$ & $84 \quad(1.2)$ & -0.3 & 77 (1.6) & 85 (1.8) & 1.3 \\
\hline I20.0 (Unstable angina) & 318 & $(3.4)$ & $340 \quad(3.7)$ & 1.3 & 111 & 130 & 2.1 & 121 & $116 \quad(2.5)$ & -0.7 \\
\hline I21 (Acute myocardial infarction) & 233 & $(2.5)$ & $261 \quad(2.8)$ & 1.9 & 116 & $136(2.0)$ & 2.2 & $92 \quad(2.0)$ & $110(2.4)$ & 2.6 \\
\hline $\begin{array}{l}\text { I24 (Other acute ischaemic heart } \\
\text { diseases) }\end{array}$ & 30 & $(0.3)$ & $33 \quad(0.4)$ & - & $18 \quad(0.3)$ & $16 \quad(0.2)$ & - & $14 \quad(0.3)$ & $19(0.4)$ & - \\
\hline
\end{tabular}




\begin{tabular}{|c|c|c|c|c|c|c|c|c|c|c|c|c|c|c|c|}
\hline & & $\begin{array}{c}\text { Clopidogrel } \\
\mathbf{n}=9224\end{array}$ & & $\begin{array}{l}\text { icagrelor } \\
=9224\end{array}$ & $\begin{array}{l}\text { Standardized } \\
\text { Difference } \\
(\%)\end{array}$ & & $\begin{array}{l}\text { rasugrel } \\
=6752\end{array}$ & & $\begin{array}{l}\text { cagrelor } \\
=6752\end{array}$ & $\begin{array}{l}\text { Standardized } \\
\text { Difference } \\
(\%)\end{array}$ & & $\begin{array}{l}\text { pidogrel } \\
=4676\end{array}$ & & $\begin{array}{l}\text { rasugrel } \\
=4676\end{array}$ & $\begin{array}{l}\text { Standardized } \\
\text { Difference } \\
(\%)\end{array}$ \\
\hline $\begin{array}{l}\text { I22 (Subsequent myocardial infar } \\
\text { ction) }\end{array}$ & 7 & $(0.1)$ & 3 & $(0.0)$ & - & 4 & $(0.1)$ & 3 & $(0.0)$ & - & 1 & $(0.0)$ & 4 & $(0.1)$ & - \\
\hline $\begin{array}{l}\text { I23 (Certain current complication } \\
\text { s following acute myocardial infarc } \\
\text { tion) }\end{array}$ & 1 & $(0.0)$ & 0 & $(0.0)$ & - & 0 & $(0.0)$ & 0 & $(0.0)$ & - & 2 & $(0.0)$ & 0 & $(0.0)$ & - \\
\hline At least one dispensing in the year $b$ & re index & x ACS hospital & alisatio & on, $\mathrm{n}(\%)$ & & & & & & & & & & & \\
\hline Any dispensing & 8757 & $(94.9)$ & 8741 & $(94.8)$ & -0.8 & 6085 & $(90.1)$ & 6122 & $(90.7)$ & 1.9 & 4326 & $(92.5)$ & 4302 & $(92.0)$ & -1.9 \\
\hline $\begin{array}{l}\text { At least one dispensation of APA } \\
\text { excluding heparin (ATC code B01A } \\
\text { C) }\end{array}$ & 3556 & $(38.6)$ & 3482 & $(37.7)$ & -1.7 & 1641 & $(24.3)$ & 1582 & $(23.4)$ & -2.1 & 1483 & $(31.7)$ & 1461 & $(31.2)$ & -1.0 \\
\hline $\begin{array}{l}\text { At least one dispensation of acetyls } \\
\text { alicylic acid * }\end{array}$ & 2991 & $(32.4)$ & 2976 & $(32.3)$ & -0.3 & 1424 & (21.1) & 1382 & $(20.5)$ & -1.5 & 1275 & $(27.3)$ & 1255 & (26.8) & -1.0 \\
\hline $\begin{array}{l}\text { At least one dispensation of clopid } \\
\text { ogrel (ATC codes B01AC04, B01AC } \\
\text { 30) }\end{array}$ & 1462 & (15.8) & 1419 & $(15.4)$ & -1.3 & 580 & (8.6) & 576 & (8.5) & -0.2 & 650 & (13.9) & 604 & $(12.9)$ & -2.9 \\
\hline $\begin{array}{l}\text { At least one dispensation of Prasug } \\
\text { rel (ATC code B01AC22) }\end{array}$ & 62 & $(0.7)$ & 71 & $(0.8)$ & - & 100 & (1.5) & 84 & $(1.2)$ & - & 76 & (1.6) & 95 & $(2.0)$ & - \\
\hline $\begin{array}{l}\text { At least one dispensation of Ticagr } \\
\text { elor (ATC code B01AC24) }\end{array}$ & 34 & $(0.4)$ & 39 & $(0.4)$ & - & 21 & (0.3) & 13 & $(0.2)$ & - & 14 & $(0.3)$ & 13 & $(0.3)$ & - \\
\hline
\end{tabular}

At least one of the following cardiac risk factors in the year before index ACS hospitalisation, $\mathrm{n}(\%)$ 


\begin{tabular}{|c|c|c|c|c|c|c|c|c|c|c|c|c|c|c|c|}
\hline & & $\begin{array}{c}\text { Clopidogrel } \\
\mathrm{n}=9224\end{array}$ & & $\begin{array}{l}\text { icagrelor } \\
=9224\end{array}$ & $\begin{array}{l}\text { Standardized } \\
\text { Difference } \\
(\%)\end{array}$ & & $\begin{array}{l}\text { Prasugrel } \\
n=6752\end{array}$ & & $\begin{array}{l}\text { icagrelor } \\
=6752\end{array}$ & $\begin{array}{c}\text { Standardized } \\
\text { Difference } \\
\text { (\%) }\end{array}$ & & $\begin{array}{l}\text { pidogre } \\
=4676\end{array}$ & & $\begin{array}{l}\text { rasugrel } \\
\mathrm{l}=4676\end{array}$ & $\begin{array}{l}\text { Standardized } \\
\text { Difference } \\
(\%)\end{array}$ \\
\hline Diabetes mellitus & 2071 & $(22.5)$ & 2002 & $(21.7)$ & -1.8 & 1303 & $3(19.3)$ & 1183 & $(17.5)$ & -4.6 & 991 & $(21.2)$ & 1001 & $(21.4)$ & 0.5 \\
\hline Hypertension & 1654 & $(17.9)$ & 1583 & $(17.2)$ & -2.0 & 683 & $(10.1)$ & 602 & $(8.9)$ & -4.1 & 632 & $(13.5)$ & 637 & $(13.6)$ & 0.3 \\
\hline Coronary artery disease (CAD) & 1253 & $(13.6)$ & 1284 & $(13.9)$ & 1.0 & 578 & $3(8.6)$ & 604 & $(8.9)$ & 1.4 & 526 & $(11.2)$ & 540 & $(11.5)$ & 0.9 \\
\hline Congestive heart failure & 315 & $(3.4)$ & 300 & $(3.3)$ & -0.9 & 103 & $3(1.5)$ & 100 & $(1.5)$ & -0.4 & 102 & $(2.2)$ & 109 & $(2.3)$ & 1.0 \\
\hline Peripheral arterial disease (PAD) & 422 & $(4.6)$ & 431 & $(4.7)$ & 0.5 & 178 & $(2.6)$ & 184 & $(2.7)$ & 0.6 & 165 & $(3.5)$ & 163 & $(3.5)$ & -0.2 \\
\hline Acute coronary syndrome (ACS) & 652 & (7.1) & 669 & $(7.3)$ & 0.7 & 262 & $(3.9)$ & 300 & $(4.4)$ & 2.8 & 249 & $(5.3)$ & 260 & $(5.6)$ & 1.0 \\
\hline Ischemic or undefined stroke & 192 & $(2.1)$ & 158 & $(1.7)$ & - & 46 & $5 \quad(0.7)$ & 62 & $(0.9)$ & - & 50 & $(1.1)$ & 49 & $(1.0)$ & - \\
\hline Major bleeding & 142 & $(1.5)$ & 130 & $(1.4)$ & - & 62 & $(0.9)$ & 61 & $(0.9)$ & - & 52 & $(1.1)$ & 59 & $(1.3)$ & - \\
\hline \multicolumn{16}{|c|}{ At least one of the following other comorbidities in the year before index ACS hospitalisation, $n$ (\%) } \\
\hline Active cancer & 1022 & $(11.1)$ & 1023 & $(11.1)$ & 0.0 & 433 & (6.4) & 402 & $(6.0)$ & -1.9 & 372 & $(8.0)$ & 374 & $(8.0)$ & 0.2 \\
\hline Abnormal renal function & 224 & $(2.4)$ & 232 & $(2.5)$ & 0.6 & 84 & $(1.2)$ & 76 & $(1.1)$ & -1.1 & 104 & $(2.2)$ & 88 & $(1.9)$ & -2.4 \\
\hline $\begin{array}{l}\text { Chronic obstructive pulmonary } \\
\text { disease (COPD) }\end{array}$ & 226 & $(2.5)$ & 224 & $(2.4)$ & -0.1 & 96 & $5 \quad(1.4)$ & 89 & $(1.3)$ & -0.9 & 81 & $(1.7)$ & 94 & $(2.0)$ & 2.1 \\
\hline Abnormal liver function & 102 & (1.1) & 80 & $(0.9)$ & - & 60 & (0.9) & 66 & (1.0) & - & 77 & (1.6) & 49 & (1.0) & - \\
\hline
\end{tabular}




\section{OUTCOMES}

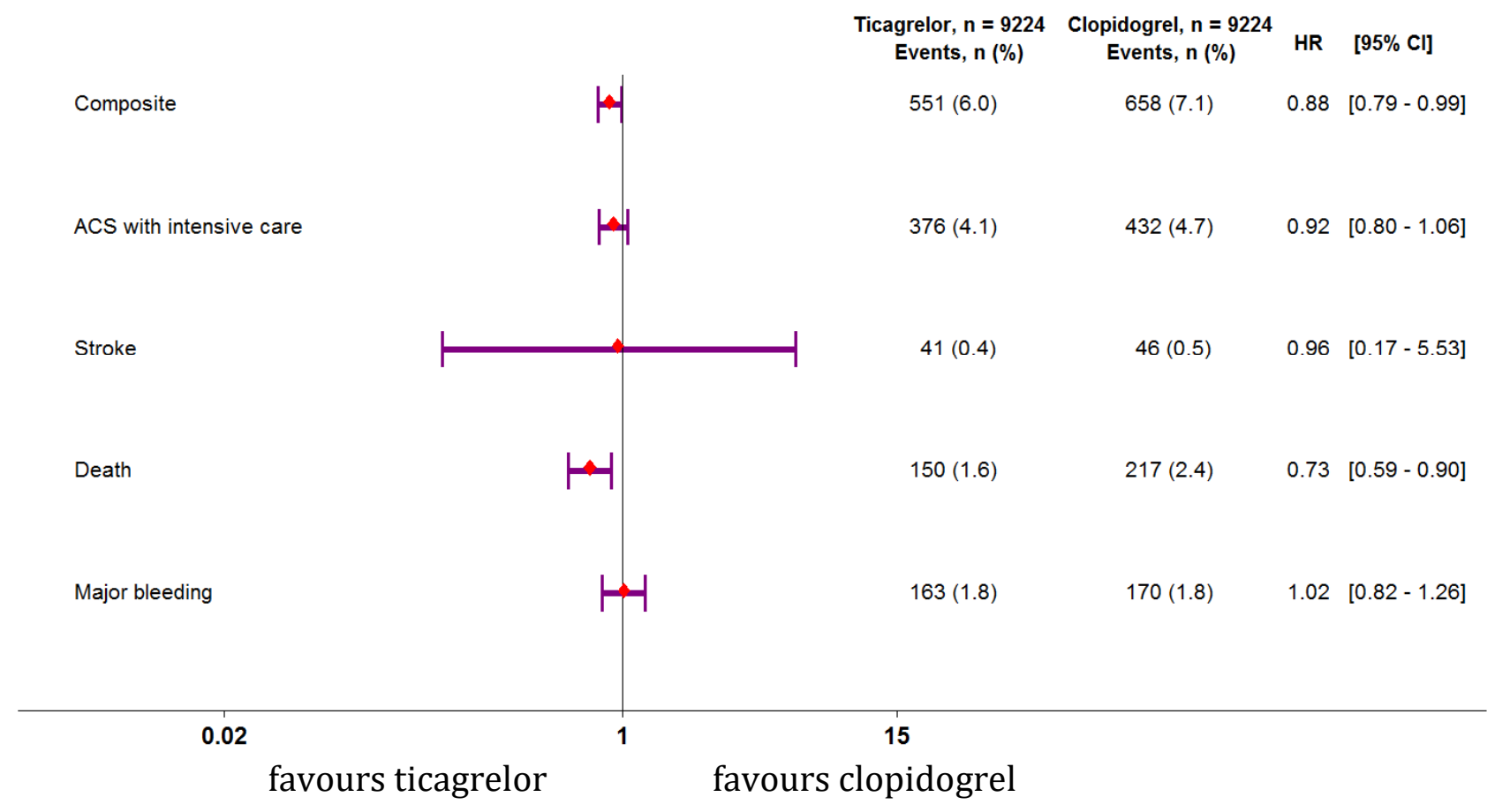

Figure 1 Hazard ratios with 95\% CI, ticagrelor vs. clopidogrel in the hdPS-matched populations 


\section{OUTCOMES}

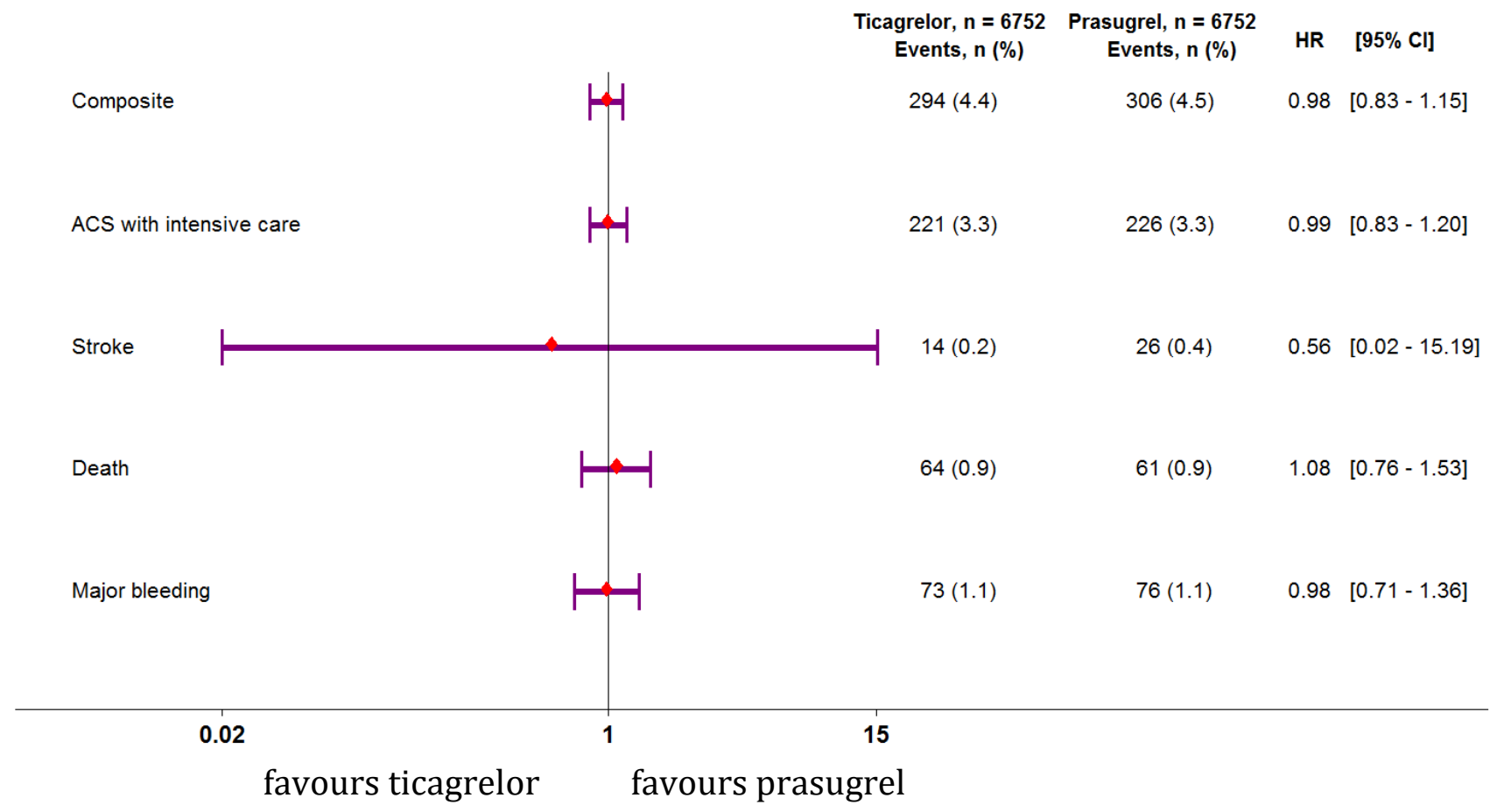

Figure 2 Hazard ratios with 95\% CI, ticagrelor vs. prasugrel in the hdPS-matched populations 


\section{OUTCOMES}

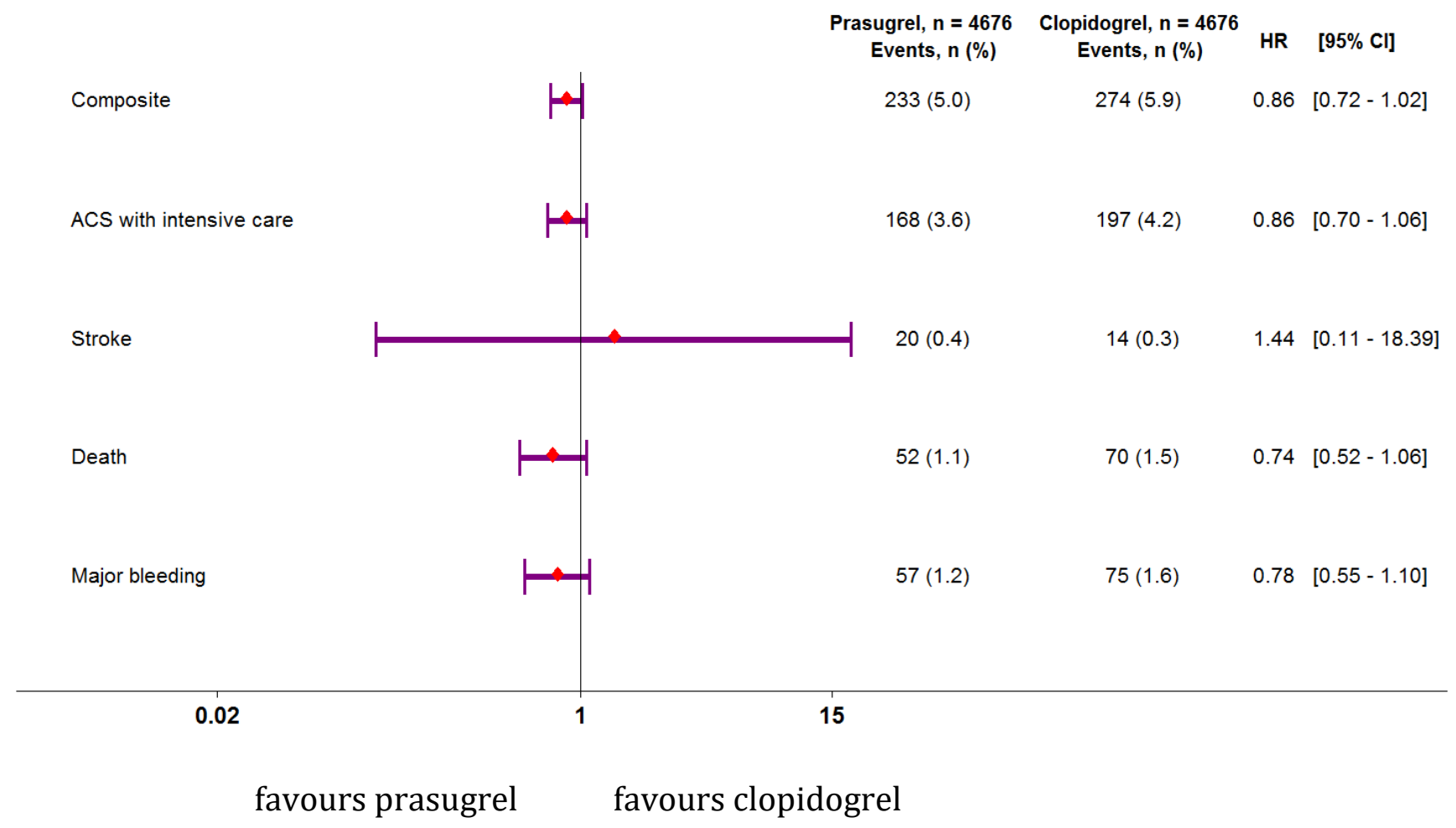

Figure 3 Hazard ratios with 95\% CI, prasugrel vs. clopidogrel in the hdPS-matched populations 
Graphical abstract

Hazard ratios with $95 \% \mathrm{Cl}$, in matched ticagrelor vs. clopidogrel (left), ticagrelor vs. prasugrel (middle) and prasugrel vs. clopidogrel patients, for the secondary prevention of outcomes after acute coronary syndrome in the French population

\section{OUTCOMES}

Composite

ACS with intensive care

Stroke

Death

Major bleeding ticagrelor vs. clopidogrel

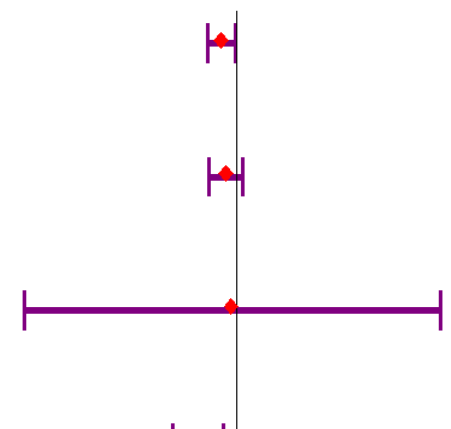

Ticagrelor vs. prasugrel

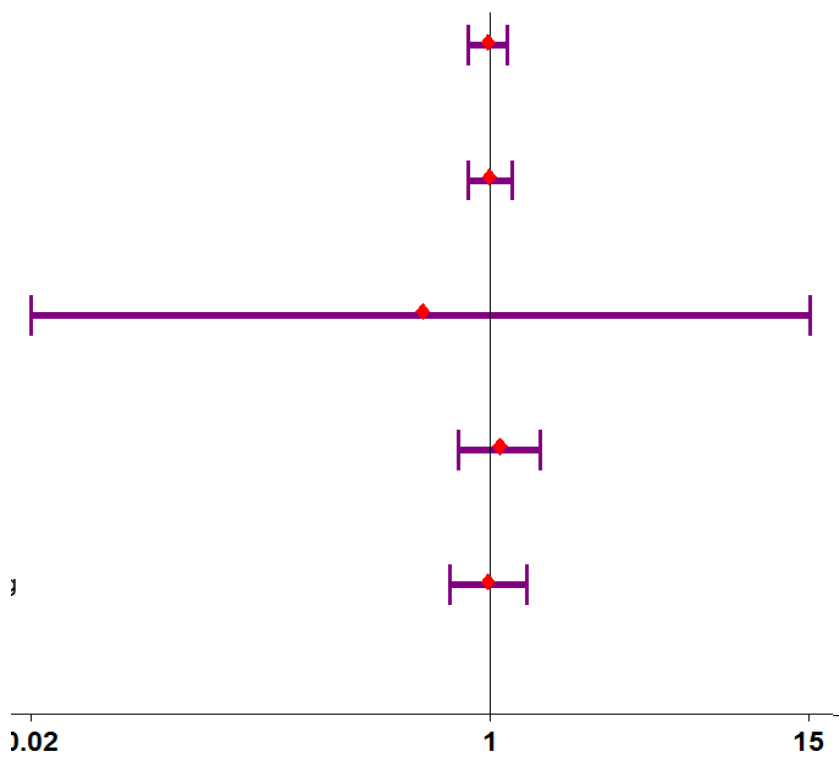

prasugrel vs. clopidogrel

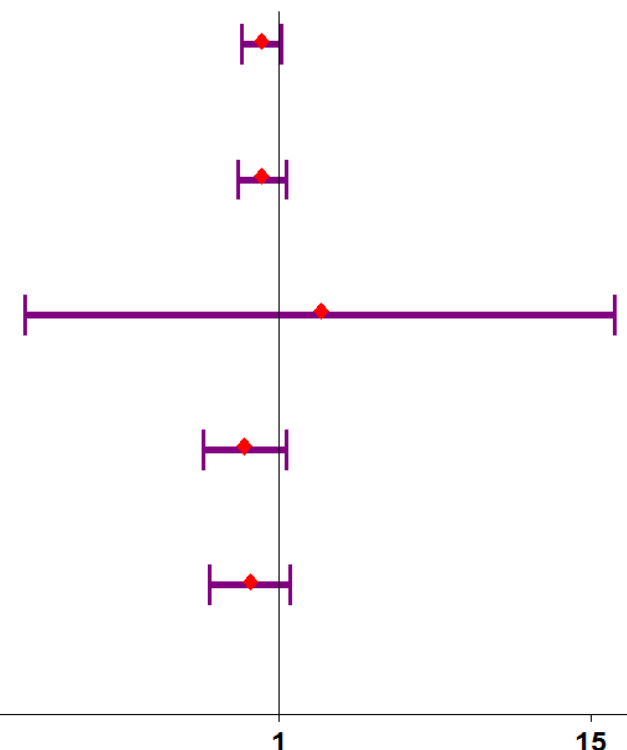

Required parameters are missing or incorrect. Required parameters are missing or incorrect. 